
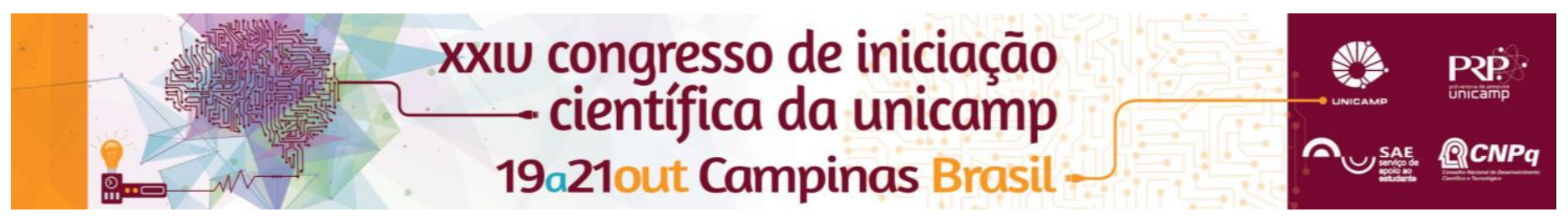

\title{
Estudo da relação entre níveis séricos de proteína c-reativa em indivíduos atletas e sedentários com lesão da medula espinhal.
}

Carlos A. Ferreira*, Anselmo A. Costa e Silva, Diego T. Brunelli, Guilherme F. Marginador, Mara Patrícia T. C. Mikahill, Alberto Cliquet Junior, José I. Gorla, Cláudia R. Cavaglieri.

\begin{abstract}
Resumo
Atualmente na América do Sul, estima-se uma ocorrência de 25 casos de lesão traumática por milhão de habitantes. As principais causas são por doenças cardiovasculares e metabólicas. Assim, o exercício tem se mostrado um fator para a melhora do perfil inflamatório em sujeitos com LME. O objetivo do estudo foi de comparar a concentração sérica em indivíduos com LME. Foram analisados um total de 25 sujeitos divididos em 4 grupos, de acordo com atividade e nível da lesão. Como resultado, é apresentada uma maior concentração nos atletas com paraplegia em comparação com os sedentários, o que diverge da tendência da redução dos níveis séricos de PCR em função dos efeitos crônicos do exercício. Conclui-se que os atletas paraplégicos com LME apresentaram concentrações elevadas de PCR em comparação com o grupo sedentário., devido a carga de treinamento ter sido muito alta previamente a coleta, sendo o tempo de recuperação insuficiente para restauração dos valores basais.
\end{abstract}

\section{Palavras-chave}

Lesão da Medula Espinhal; Inflamação; Síndrome Metabólica

\section{Introdução}

Atualmente na América do Sul, estima-se uma ocorrência de 25 casos de lesão traumática por milhão de habitantes. As principais causas das mortalidades são por doenças cardiovasculares e metabólicas, particularmente devido as mudanças relacionadas a composição corporal ginóide (perda significante da massa magra, e aumento na massa gorda na região do tronco e abdômen), acompanhado da falta da atividade física, induzindo a síndrome metabólica, que consequentemente aumenta os riscos das doenças crônicas não transmissíveis. Assim, o exercício tem se mostrado um fator importante para a melhora do perfil inflamatório em indivíduos com LME. O objetivo do estudo foi de analisar a concentração sérica da Proteína C-Reativa (PCR) em indivíduos sedentários com lesão (para e tetraplegia) e comparar com indivíduos lesionados que praticam exercício.

\section{Resultados e Discussão}

Participou do estudo um total de 25 sujeitos, com idade entre 24 e 45 anos, os quais foram divididos em 4 grupos, de acordo com o nível da sua lesão, e seu nível de atividade física, sendo eles: G1: Paraplégico Atleta $(n=8) ;$ G2: Tetraplégico Atleta $(n=7)$; G3: Paraplégico Sedentário $(n=7)$; G4: Tetraplégico Sedentário $(n=3)$. Para a determinação de níveis séricos de PCR, a coleta de sangue foi realizada em jejum de 12 horas com no mínimo 48 horas após a última sessão de treino dos atletas. Foi utilizado o método ELISA, em duplicatas, para maior precisão nos resultados. As amostras foram coletadas durante o período de outubro de 2015 até maio de 2016, no Hospital das Clínicas, e na Faculdade de Educação Física, ambas dispostas na Unicamp.

Tabela 1. Média e desvio padrão $( \pm)$ dos níveis séricos de PCR em mg/L.

\begin{tabular}{cll} 
Grupos & Atletas & Sedentários \\
Paraplégicos $(n=15)$ & $7.43^{*}( \pm 3.14)$ & $2.68( \pm 1.98)$ \\
Tetraplégicos $(n=10)$ & $4.19( \pm 2.37)$ & $4.76( \pm 4.22)$ \\
\hline
\end{tabular}

DOI: 10.19146/pibic-2016-51858

\author{
* Denota diferença estatisticamente significativa em comparação \\ aos paraplégicos sedentários.
}

A análise dos dados mostrou que o grupo de atletas com paraplegia apresentou valores significativamente maiores em comparação ao grupo de atletas sedentários. Este resultado é inesperado em virtude da tendência de redução dos níveis séricos de PCR em função dos efeitos crônicos do exercício. Em contrapartida, sabe-se que há uma atenuação na produção e secreção das proteínas de fase aguda, especialmente a PCR, após o treinamento de alta intensidade (KASAPIS; THOMPSON, 2005). Sendo assim, a intensidade e o volume de treino destes atletas (prévio a coleta de sangue), podem ter sido elevados de modo que o tempo de recuperação (48horas) não fosse o suficiente para que a PCR retornasse aos valores basais para a coleta, o que justifica os elevados valores observados na amostra deste estudo. No estudo a variável alimentação não foi controlada neste estudo, de modo que não se pode descartar a influência de fatores ligados ao consumo alimentar sobre os níveis de PCR.

\section{Conclusões}

Todos os grupos obtiveram concentrações altas de PCR, entretanto os atletas paraplégicos tiveram uma maior concentração devida provavelmente à carga de treino alta previamente a coleta dos dados, ou o período de recuperação insuficiente para restaurar os níveis basais.

\section{Agradecimentos}

Gostaria de agradecer ao apoio da FAPESP (2015/13932-4) e a FAEPEX.

\footnotetext{
1- Curtis, M. D.; Shiu, K.; Butler, W. M. e Huffmann, J. C. J. Am Chem. Soc. 1986, 108, 3335.

2- Kasapis C, Thompson PD: The effects of physical activity on serum C-reactive protein and inflammatory markers: A systematic review. J Am Coll Cardiol 45: 1563-1569, 2005
} 